\title{
MECHANICAL DESIGN ANALYSIS AND IMPROVEMENT OF ALUMINIUM ALLOY CANTAS SICKLE BLADE USING FINITE ELEMENT METHOD SIMULATION
}

\section{AHMAD SYAZWAN RAMLI'; MOHD AZWAN MOHD BAKRI'; MOHD RIZAL AHMAD ${ }^{1}$ and MOHD IKMAL HAFIZI AZAMAN ${ }^{1}$}

\begin{abstract}
This article explores the possibility of improving the design of CANTAS, by focusing on the failure analysis and the design optimisation of its sickle blade. The sickle blade material was replaced with 6262-T8 aluminium alloy. An analysis to inspect the sickle's mechanical strength against $300 \mathrm{~N}$ of cutting force was simulated using the finite element method (FEM) software. The total stress experienced by the new design (i.e., 1204 $\mathrm{MPa}$ ) exceeded the material's ultimate tensile strength of $390 \mathrm{MPa}$; therefore, would break due to mechanical failure. The dimension of the weak point on the sickle was then increased to 25\%. The improved sickle design only experienced $314 \mathrm{MPa}$ of stress and did not exceed its ultimate tensile strength. The design was further optimised to reduce its weight. A reduction of $14 \%$ was achieved compared to the previous improved design and $69.7 \%$ compared to the original spring steel sickle with only $352 \mathrm{MPa}$ of stress experienced. It also can withstand any directional impact force in drop test simulation. The aluminium alloy sickle is also $48 \%$ cheaper than spring steel sickle. However, a cost per tonne of productivity calculation shows that the performance of both sickle materials is very much the same.
\end{abstract}

\section{Keywords: agriculture, design, FEM analysis, palm oil, sickle.}

Received: 24 May 2021; Accepted: 22 November 2021; Published online:

\section{INTRODUCTION}

Oil palm has been cultivated due to its high oil yield per unit area of plantation (Basiron, 2007). It is the main commodity crop of Malaysia, with export revenue reaching more than RM67.12 billion in 2018 (Parveez, 2020). In palm oil plantations, harvesting fresh fruit bunch (FFB) from palm trees is still a major challenge that needs to be solved. Therefore, a motorised oil palm cutter named CANTAS has been developed to address this issue (Figure 1) (Ahmad et al., 2020). By using CANTAS, the productivity of an oil palm plantation can

\footnotetext{
Malaysian Palm Oil Board,

6 Persiaran Institusi, Bandar Baru Bangi,

43000 Kajang, Selangor, Malaysia.

* Corresponding author e-mail: ahmad.syazwan@mpob.gov.my
}

be increased; therefore, reducing the number of labours required for the plantation's operation. The cutter consists of a sickle on a pole that vibrates using a petrol engine, and was later substituted with an electric motor to ease and facilitate FFB cutting during harvesting.

The latest version of CANTAS is named CANTAS Electro, and it runs on a fully electric power supplied by two units of lithium-ion batteries. However, further optimisation and improvement measures can be done to enhance the efficiency of CANTAS. Jelani et al. (2008) improved the CANTAS technology by introducing CANTAS Evo version, which has a new cutting head design, engine, pole gripper and shaft guider. However, the sickle design improvement was not addressed in his study. The CANTAS's sickle improvement design was done a few years earlier by the introduction of the 'C-shaped' sickle 
profile, which was found to be more efficient and able to reduce vibrations during harvesting (Jelani et al., 2008). However, the study only focused on the performance of the new sickle profile and did not consider other materials for it. The sickle has to be as light as possible to reduce its vibration because a high momentum is generated by a heavier sickle (Jelani et al., 2008). Lighter sickle also translates to less inertia, and therefore, less effort is needed to provide the motion for the sickle's vibration; thus, increasing its cutting efficiency (Jelani et al., 2008; Winn, 2010). In addition, too much vibration increases tool wear, and decreases geometric accuracy and surface finish (Rusinek et al., 2014). Other than that, Hand Arm Vibration Syndrome (HAVS) is a common illness that is associated with regular and frequent exposure to vibration tools, such as CANTAS (Salleh et al., 2013). Hence, the sickle blade used for FFB harvesting needs to be robust and strong enough against wear and tear. This is because the oil palm frond, for example, contains a very high amount of lignin and silica (Dahlan, 2000). These elements found in palm oil fronds have the potential to wear out the sickle blade.

So far, there has been little discussion about sickle design optimisation. Therefore, this article intends to investigate the possibility of further improving the sickle blade design. In this research, the CANTAS sickle blade made of AISI 5160 high carbon steel, also commonly known as spring steel, was replaced by aluminium alloy with the goal of reducing the weight of the CANTAS to improve its ergonomic design, as well as increasing its durability.

\section{MATERIALS AND METHODS}

\section{Material Selection}

The CANTAS sickle blade is currently made of AISI 5160 high carbon steel material. This material is also commonly known as spring steel due to its application in the automotive industry for various heavy duty spring applications (The Material World, 2020). Besides, spring steel is also commonly used as a material to produce cutting tools, such as sickles, machetes, and various forms of knives used in the agriculture industry.

However, similar to other types of steel, spring steel is prone to corrosion due to rust. The rust is developed via oxidation of elements, such as the iron content in spring steel with oxygen and water in the surrounding environment. Steel corrosion due to rust weakens the structural strength of a steel tool; hence, making the tool prone to mechanical failure. Moreover, the high density of steel means that any tools made of it would be heavy. A heavy sickle on a pole like the CANTAS design would cause a stability issue when the operator handles the CANTAS during harvesting. The operator would also require extra energy to handle the high momentum force and inertia generated by the weight of the sickle multiplied with the length of the pole. This situation would also cause difficulties in manoeuvring the CANTAS efficiently during operation. Therefore, it would be advantageous if a lightweight material could be used as the CANTAS sickle blade, in order to reduce the stability and manoeuvring issues due to the heavier weight of a steel sickle.

To solve these issues, aluminium alloy is suggested as a replacement material for the sickle blade. Aluminium is a common metal used for lightweight applications due to its high strength-toweight ratio compared to other metals. Aluminium is also ductile, which is the opposite property of brittle; therefore, aluminium deforms first before material failure occurs (Gunturi et al., 2019). A brittle material does not deform, but breaks and cracks instantly when the stress exceeds its tensile strength (Andreoni and Yip, 2020). The crack initiation and propagation resulted from the fatigue of the material, is a major source of a component's failure (Lin and Smith, 1998).

For the sickle application, the 6262-T8 aluminium alloy grade was chosen due to its high tensile ultimate strength (i.e., $390 \mathrm{MPa}$ ) compared to

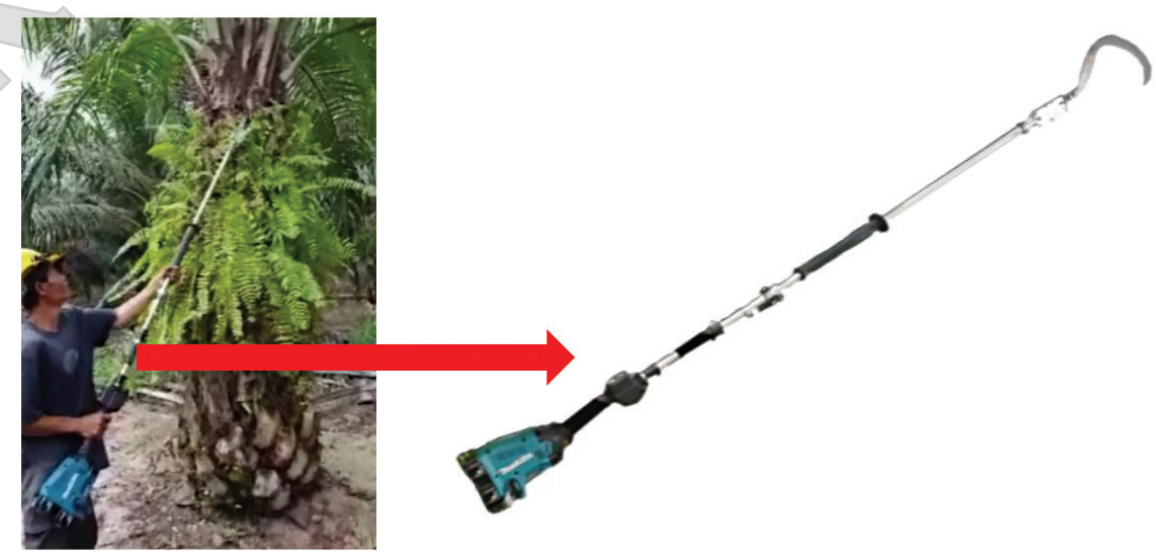

Figure 1. CANTAS, a motorised oil palm tree harvester. 
other aluminium alloy grades (MakeItFrom, 2019). Besides, aluminium is resistant to corrosion. The oxidation of aluminium produces an aluminium oxide layer that protects the material from further oxidation through a chemical process known as passivation (Kuznetsova et al., 2001). Therefore, aluminium will not corrode or face any structural weakening issues like rust. These advantages are the main reasons for selecting aluminium alloy as the replacement material for the spring steel of the CANTAS sickle blade.

\section{Analysis Method}

Finite element method (FEM) simulation. In order to determine the mechanical strength of the sickle blade using aluminium alloy, a failure analysis with the help of FEM simulation was conducted using ANSYS software. The failure simulation analysis was conducted because this kind of analysis is able to identify any failure that might have occurred if such parameter (i.e., material replacement) is applied to the current design, as well as enabling any suggestion to avoid the failure to be verified in an efficient way (Zerbst et al., 2015). The simulation can predict the mechanical structural behaviour of a defined structure or an object based on the assigned loads, physical surroundings, and physical design shape using partial differential equations (Harish, 2019).

This method enables engineers and designers to check the suitability and rigidity of their designed object via computer simulation instead of building a prototype first. This approach can also reduce the initial cost of building the prototype by producing an almost identical design and reducing any possible occurrence of mechanical failure.

The first step in conducting FEM simulation is preparing the three-dimensional (3D) computeraided drawing (CAD) of the sickle blade. Figure 2 shows the dimension of the sickle and the thickness of the blade which is set to $1.2 \mathrm{~mm}$. Once the sickle blade was designed, the CAD was uploaded and generated in the pre-processing stage of the software. At this stage, a mesh generation tool was used to convert the sickle design into smaller elements. This step is done so that the software can assign the FEM algorithm to each element of the sickle. The mesh size is chosen to be $1 \mathrm{~mm}$ which generates 698460 nodes and 364030 elements due to the factor of computer processing power limitation. Then, all loads exerted on the sickle, as well as the physical and mechanical properties of the chosen materials (i.e., AISI 5160 high carbon spring steel and 6262-T8 aluminium alloy), were assigned to the 3D sickle model. The simulation results for the spring steel were set as the benchmark for comparison with the simulation results of the aluminium alloy. For this analysis, a cutting force of $300 \mathrm{~N}$ was assigned at the sharp edge of the sickle blade and the fixed support at the bottom neck of the sickle, as shown in Figure 2 (Jelani et al., 1998).

After that, the computational tool in the software performed an engineering analysis on the mechanical structural strength of the sickle blade once the simulation was run. The sickle design was then further optimised with the aid of FEM simulation to determine the mechanical structural strength of each sickle design improvement.

Design improvement. Once the simulation result is obtained, the design is further assessed to detect any potential failure or damage. If failure is detected, new design improvements using 3D CAD software can be done to modify the geometry and profile of the sickle design, so that the identified weak point can be eliminated. The new improved design is again verified using the FEM simulation analysis to detect any existence of weak points and possible failure regions.
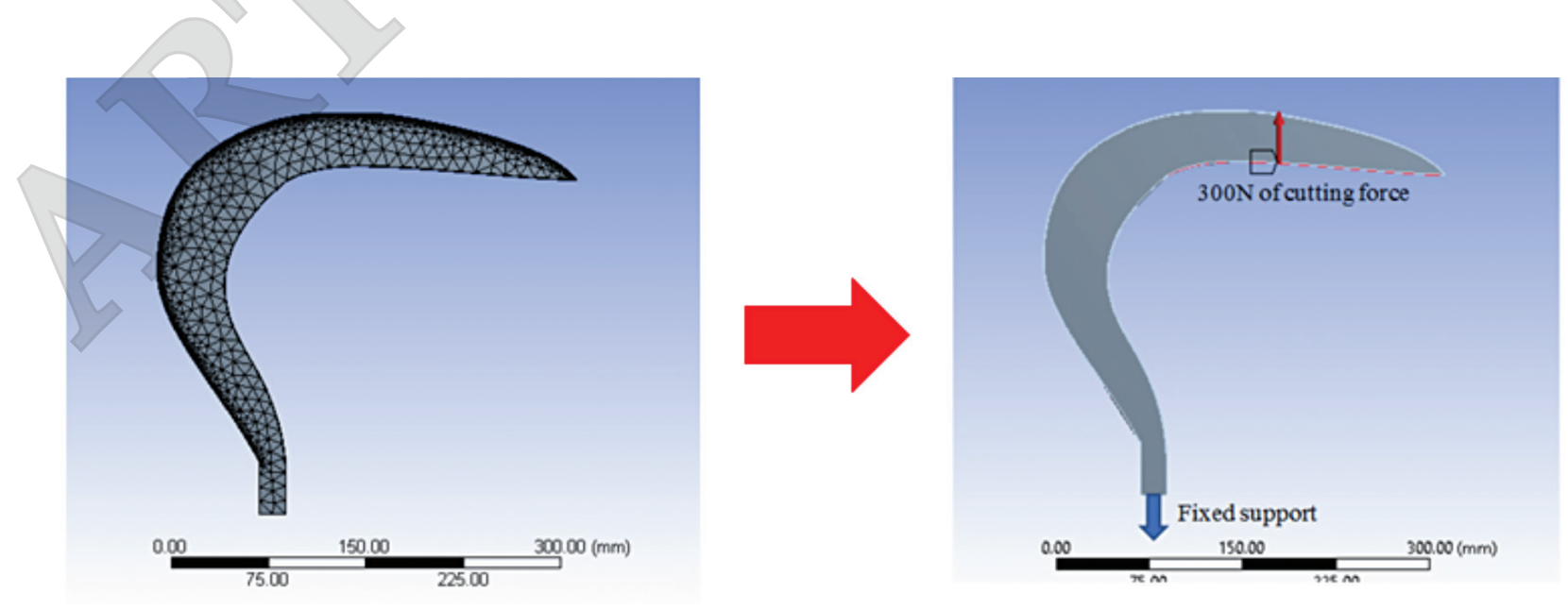

Figure 2. A meshed 3D model of sickle blade design and loads assignment. 
Drop test. Drop test simulation was also performed to verify the quality of the new sickle design. In this test, the impact load exerted on the sickle is assumed to be solely generated by the potential energy of the CANTAS based on its height when used. The impact force, $F$, was calculated using Equation (1) (Lüders et al., 2017):

$$
F=m \cdot g \cdot h
$$

The formula equates the gravitational potential energy generated from the initial height of the sickle. The potential energy is based on the formula of the multiplication of the sickle's weight, $m$, with the gravitational acceleration, $g$, and the initial height of the sickle during operation, $h$. The gravitational force, $g$ is maintained at a constant value of $9.81 \mathrm{~m} / \mathrm{s}^{2}$, whereas the height, $h$, is set at $7 \mathrm{~m}$, which is the reach of CANTAS sickle blade, with a sickle weight of $68.98 \mathrm{~g}$. If the sickle falls and hits the ground in the first three directions as specified in Table 2, it is assumed that the impact force is generated only by the weight of the sickle. However, if the sickle falls horizontally flat to the side of the sickle, then the height, $h$ is set to be $2 \mathrm{~m}$. The software calculated the amount of stress experienced by the sickle due to each impact load direction. The stress values were also compared with the material's ultimate tensile strength value to ensure the stresses generated do not break the sickle. Table 1 summarises the directions of the possible loads exerted during the drop test.

TABLE 1. POSSIBLE EXERTED LOAD DIRECTIONS DURING DROP TEST

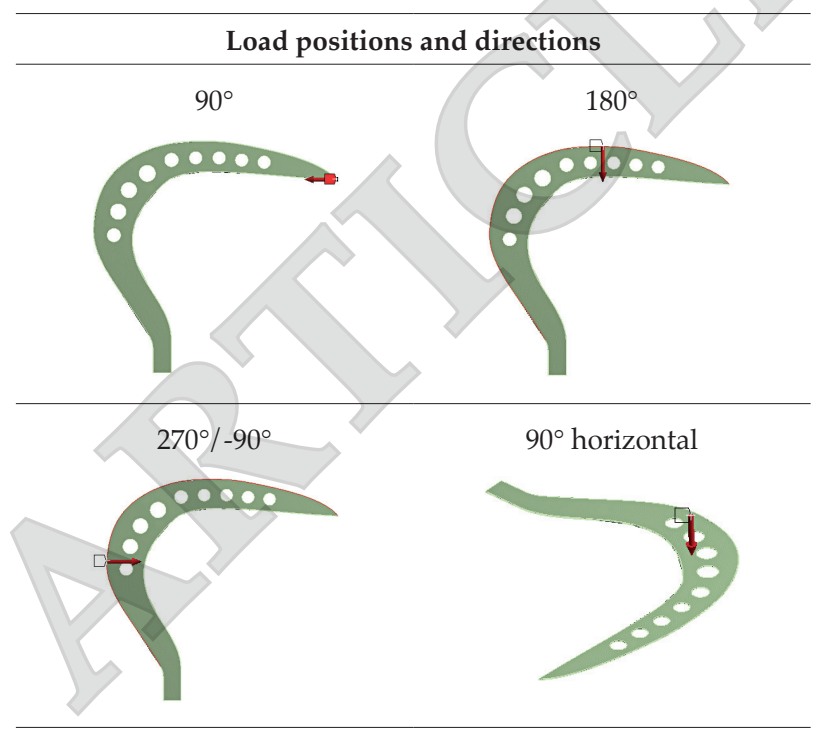

Economic analysis. Once the structural quality of the new and optimised design of the sickle has been confirmed, an economic analysis of the new aluminium alloy sickle design was carried out to verify its cost-efficiency compared to the conventional spring steel sickle. An economic analysis was done to calculate the operating cost required to harvest a ton of FFB from the plantation, and this calculation was used to assess the efficiency of the technology. If the calculated cost of the proposed technology is lower than the current operational cost per tonne of FFB of the plantation, then the proposed technology is deemed to have better cost efficiency than the current technology (Azwan et al., 2017). To estimate the price of the sickle, the price of a spring steel sickle in the current market (i.e., RM150) is considered as a benchmark price. The price of steel and aluminium generally differs based on the current global commodity price of these metals, grades, metallurgy process, and manufacturer's quotation.

Therefore, to estimate the price of this theoretical aluminium sickle, the price difference between steel and aluminium was compared using the global commodity price. On the 19 August 2020, the steel price was USD642/t, and the aluminium price was USD1749/t. Thus, the price of aluminium is $135 \%$ higher than steel. By dividing the price of the spring steel sickle with its weight (i.e., $199.58 \mathrm{~g}$ ), the value of the spring steel sickle is RM0.75/g. Based on this value, the estimated price for the aluminium sickle is $\mathrm{RM} 1.01 / \mathrm{g}$.

\section{RESULTS AND DISCUSSION}

\section{Design Simulation}

The stress and deformation values are among the simulation results that need to be analysed in this study. The stress value represents the amount of stress experienced by the sickle when subjected to the assigned load of the defined cutting force. If the stress value experienced by the sickle exceeds the sickle material's ultimate tensile strength value; thus, the load has sufficient force to cause mechanical failure to the structure. The cutting force exerted on the sickle is also high enough to break the sickle; hence, making the material unsuitable to be used for CANTAS. The deformation value of the sickle also needs to be verified. If the deformation value of the sickle blade is too high, the cutting efficiency is then reduced, and the harvesting process becomes more difficult. A material with high deformation value means that the material is highly ductile and soft, and these properties are not favourable as a cutting tool. In addition, the weight of the sickle can also be determined with the help of the 3D CAD software. Hence, by changing the material assigned to the $3 \mathrm{D}$ sickle design, the weight of the sickle with different materials can be determined and compared. Figure 3 compares the simulation results of the amount of stress experienced by the spring steel and aluminium alloy sickles, whereas Figure 4 compares the deformation experienced by both sickles based on the simulation results. 
(a)

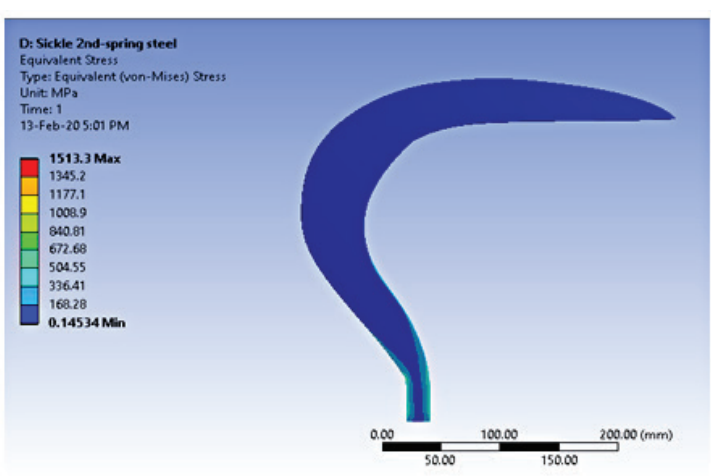

(b)

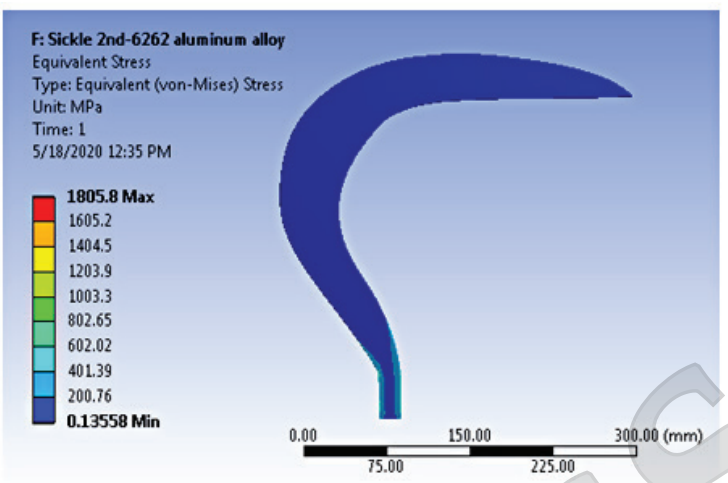

Figure 3. Comparison of stress simulation results between (a) spring steel and (b) aluminium alloy sickles.

(a)

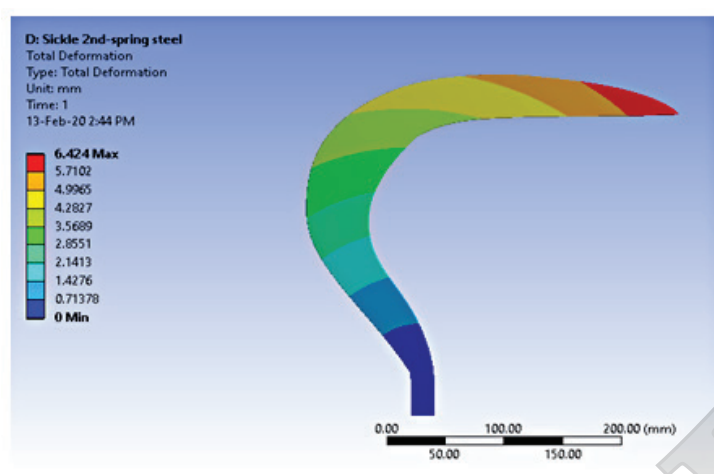

(b)

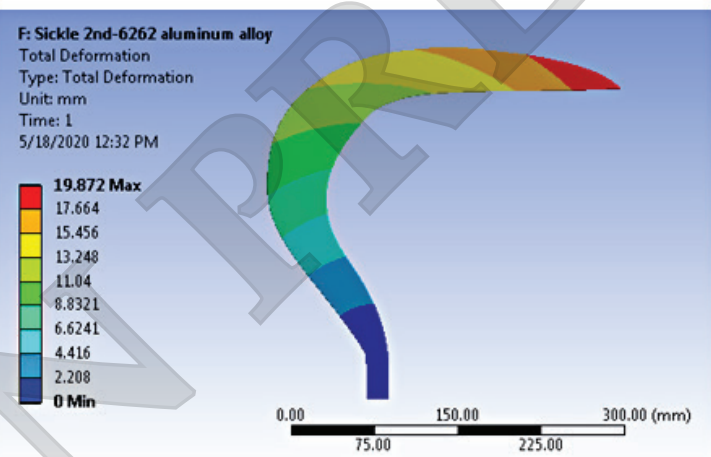

Figure 4. Comparison of deformation simulation results between (a) spring steel and (b) aluminium alloy sickles.

The amount of stress experienced by the aluminium sickle was $1203 \mathrm{MPa}$, which exceeded its ultimate tensile strength value of $390 \mathrm{MPa}$. Therefore, the aluminium sickle would break when cutting force is exerted to the sickle. Therefore, aluminium is unsuitable as sickle material for CANTAS if this design is used. The deformation value of the aluminium sickle is very high (i.e., $19.87 \mathrm{~mm}$ ), which is more than three times higher than the spring steel sickle (i.e., $6.42 \mathrm{~mm}$ ); hence, highlighting the unsuitability of this material as a sickle blade material. However, an aluminium sickle blade is very light (i.e., $68.98 \mathrm{~g}$ ), which is $65 \%$ lighter than a spring steel sickle blade, i.e. $199.58 \mathrm{~g}$, and this property is very advantageous if the material can be adapted into the design of the CANTAS sickle.

\section{Design Improvement}

Based on the graphical results, the area where mechanical failure may occur at the aluminium sickle is concentrated at the bottom neck of the sickle. It is possible to improve the design at that weak point, so that mechanical failure can be avoided. Once the design of the 3D model was improved, another FEM simulation was performed on the model to verify whether the design improvement is sufficient to avoid any mechanical failure and prevent the sickle from breaking.

The 3D CAD model of the sickle design was modified by increasing the width of the sickle neck by $25 \%$, from $20 \mathrm{~mm}$ to $25 \mathrm{~mm}$ (Figure 5). Then, the same methodology for the previous mechanical structural simulation of the sickle was implemented using the new sickle design.

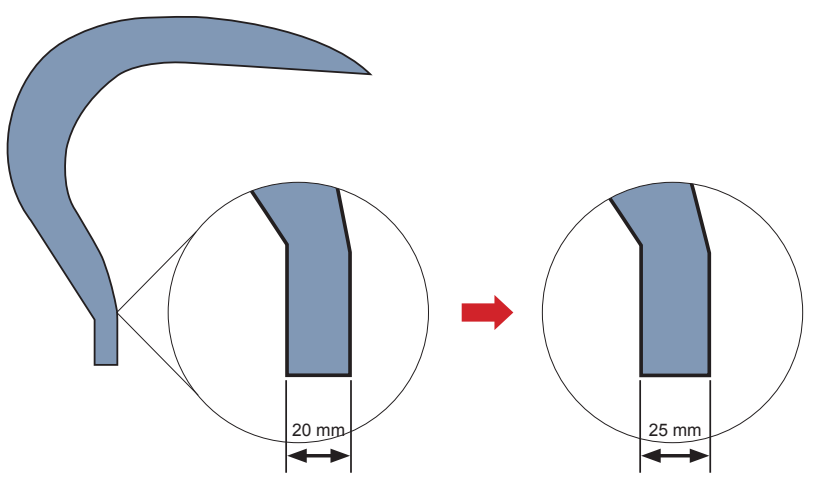

Figure 5. Design improvement to strengthen the weak point of the aluminium sickle. 
Figure 6 depicts the simulation for the stress value experienced by the improved design of the aluminium sickle. By implementing this improvement, the stress experienced by the sickle (i.e., $314 \mathrm{MPa}$ ) did not exceed its ultimate tensile strength value. Therefore, the aluminium sickle blade would not break under the defined cutting force when using the new and improved sickle blade design. However, the new design is slightly heavier (i.e., $70.45 \mathrm{~g}$ ).

In order to improve the weight of the sickle blade, its design was further improved by adding several relief holes. The holes were added accordingly at the area that did not experience any stress, as marked by the blue colour in the simulation graphic. By adding the relief holes, the weight of the sickle was reduced to $62.36 \mathrm{~g}$, which represents approximately $11 \%$ of further weight reduction.

Next, the mechanical structural strength of the further improved sickle design needs to be verified by the FEM simulation. The same method was applied to this design, similar to the previous simulation. The results in Figure 7 show that the stress experienced for this sickle design is only 356.92 MPa. Thus, the sickle did not experience any mechanical failure and it would not break when the cutting force is exerted during operation.

\section{Simulation Validation}

In order to verify the simulation result, a validation is made by a comparison with the literature. The Ramberg-Osgood (R-O) model is chosen as a comparison with the stress-strain description of the sickle model simulation (Castaldo et al., 2017). The R-O model is mostly used to estimate the non-linear relationship between strain and stress, as well as the stress-strain curve in materials near the material's yield point (Gardner and Ashraf, 2006). Figure 8 depicts a graphical representation of a R-O model of the Aluminium 6262-T8 stressstrain curve and the stress-strain curve of the FEM simulation model of the aluminium sickle.

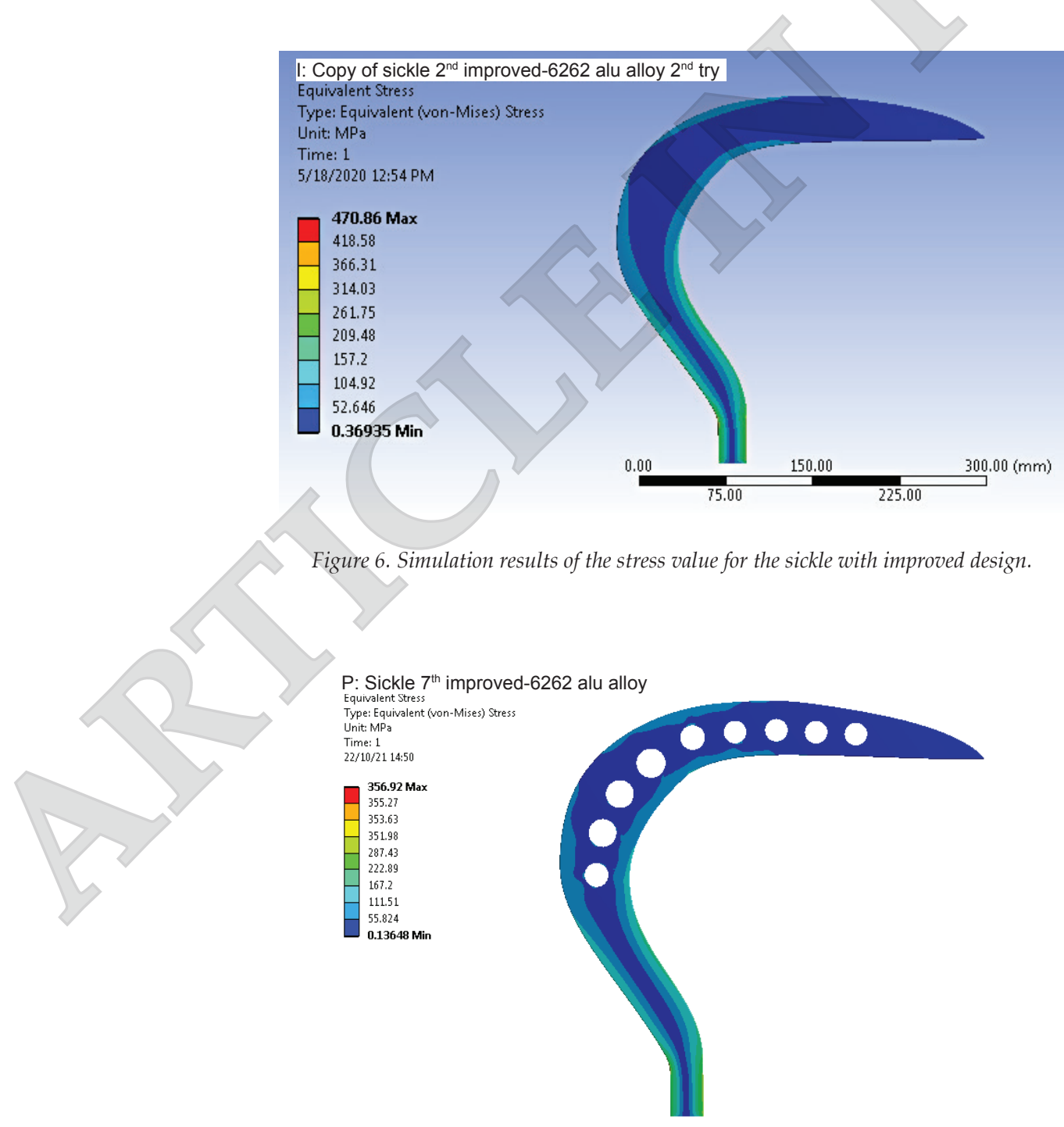

Figure 7. Simulation results of the stress value for the sickle with relief holes. 


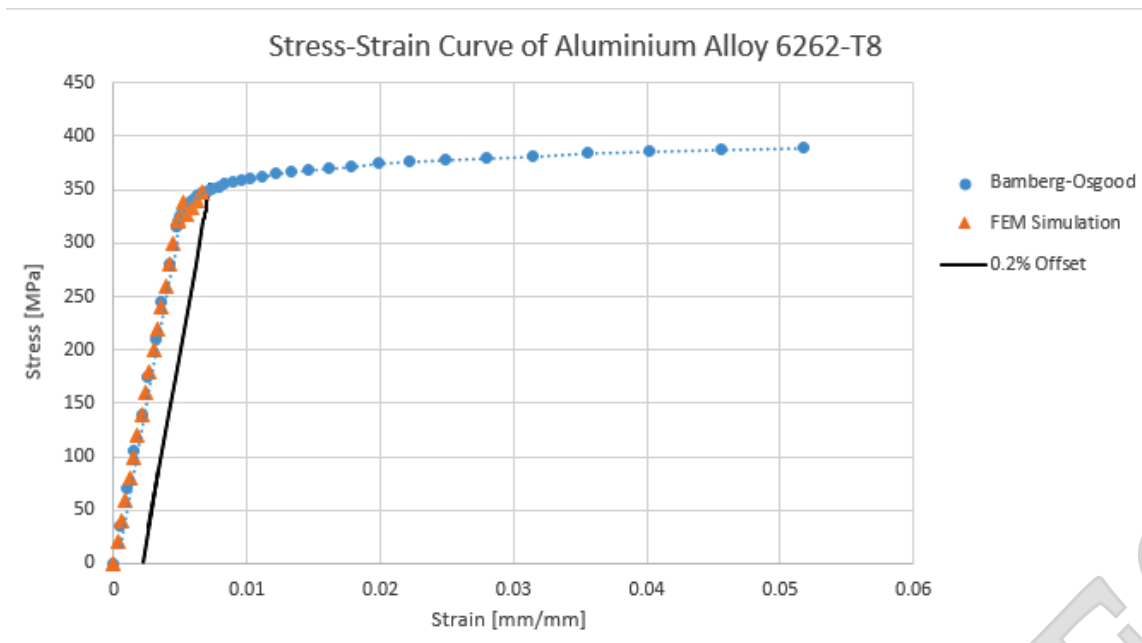

Figure 8. FEM simulation result comparison with Bamberg-Osgood model.

As shown in Figure 8, the stress-strain curve of the aluminium sickle model generated through the FEM simulation fits into the R-O model. In addition, the curve of the FEM simulation does not exceed the $0.2 \%$ offset yield strength, which means that the sickle only experiences recoverable elastic deformation. Hence, there is no irreversible elastic deformation occurring when the sickle is subjected to the cutting load.

Drop test. The result of the drop test simulation is summarised in Table 2 below by comparing the direction of the impact load exerted to the simulated stress experienced by the optimised sickle design.

As shown in Table 2, the stress generated due to the impact forces from different directions ranged from 1.17 to $131.03 \mathrm{MPa}$ and did not exceed the value of the material's ultimate tensile strength. Therefore, it can be assumed from this drop test that the aluminium alloy sickle has enough strength to handle the drop impact without causing any damage to its structure. However, a full test with a real aluminium alloy sickle prototype is needed in order to verify the simulation data result. This is because the analysis of the real failures is the main credible data that can provide important information on how the design should exactly be optimised based on available theories, fabrication details, and concept (Alonso-Martinez et al., 2019). However, with the help of FEM simulation, the number of prototypes required for the real test can be as minimal as possible, as well as identifying and narrowing down the number of weak points in the design. The results were also compared with the work conducted by Jelani et al. (2008) where they conducted a drop test at a height of $2 \mathrm{~m}$ with different dropping angles on the whole CANTAS. However, only test results with similar dropping angles were selected so that the comparison is relevant. Table 3 shows the comparison of results from Jelani et al. (2008) and this study.
As seen in Table 3, the CANTAS sickle is able to handle the drop test without causing any damage, either being dropped at $2 \mathrm{~m}$ for spring steel sickle or even at $7 \mathrm{~m}$ for aluminium alloy sickle. This means that aluminium alloy is suitable to be adopted for the CANTAS sickle design based on the FEM simulation results.

Economic analysis. Based on the price per gram chosen for this study, an aluminium sickle that weighs $68.98 \mathrm{~g}$ would be priced at RM69.84, which is $53 \%$ cheaper than the current price of spring steel sickle. However, due to the fabrication cost of extra relief holes, it is estimated that the price of the sickle would be $10 \%$ higher. Therefore, the estimated price of the aluminium sickle is approximately RM76.82, which is $48 \%$ cheaper than the spring steel sickle. For this estimated calculation, it is assumed that both sickles are fabricated using conventional machining to cut the metal into the desired sickle shape and both sickles have similar costs of additional hardening treatment. Besides, the productivity of cost per tonne of harvesting FFB using the aluminium sickle in the plantation was also calculated. The calculation is summarised in Table 4.

Based on the calculation in Table 4, the cost per tonne of FFB incurred by using the aluminium sickle is slightly cheaper than using a common spring steel sickle, which is approximately a $0.6 \%$ reduction. Even though the price difference is not very significant, other benefits of using the aluminium sickle have provided more merits and advantages when using this material, such as its lightweight property, high resistance to corrosion, and reduction of vibration generated during CANTAS operation. Therefore, using 6262-T8 aluminium alloy as the CANTAS sickle blade is more preferable and highly recommended than steel. 
TABLE 2. DROP TEST SIMULATION OF THE OPTIMISED SICKLE DESIGN

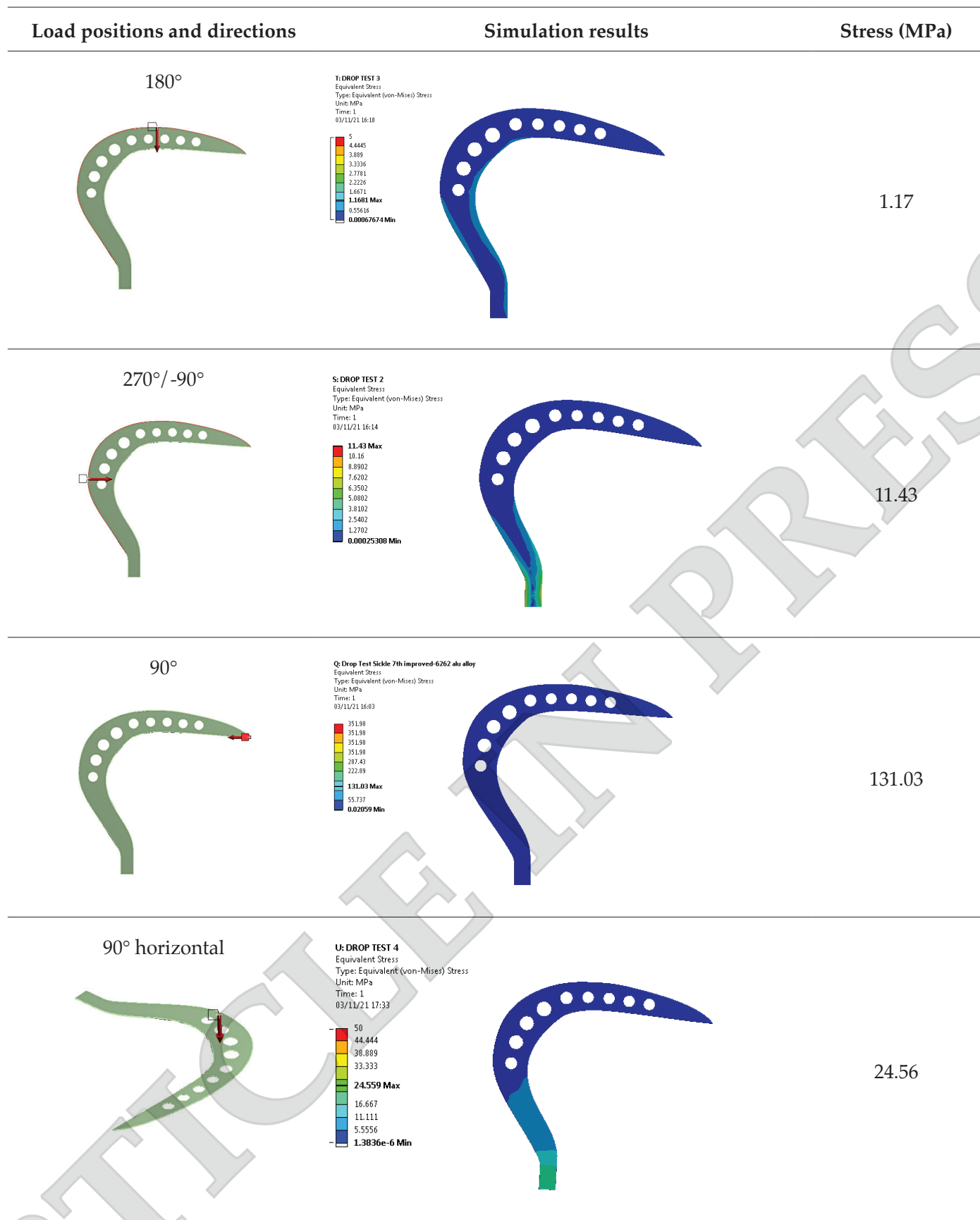

TABLE 3. COMPARISON OF SIMULATED DROP TEST WITH

\begin{tabular}{lccc}
\hline Research & Height $(\mathbf{m})$ & Dropping angle & Result \\
\hline Jelani et al. (2008) & 2 & $90^{\circ} 1^{\text {st }}$ drop & No damage \\
& 2 & $90^{\circ} 2^{\text {nd }}$ drop & No damage \\
& 2 & $90^{\circ} 3^{\text {rd }}$ drop & No damage \\
This study & 2 & $90^{\circ}$ horizontal & No damage \\
& 7 & $90^{\circ}$ & No damage \\
7 & $-90^{\circ} / 270^{\circ}$ & No damage \\
\hline
\end{tabular}

Source: Jelani et al. (2008). 
TABLE 4. THE PRODUCTIVITY COST PER TONNE OF FFB USING ALUMINIUM AND SPRING STEEL SICKLES

\begin{tabular}{|c|c|c|}
\hline \multirow{2}{*}{$\begin{array}{ll} & \text { Description } \\
\text { Sickle price } & \end{array}$} & \multicolumn{2}{|c|}{ Calculation } \\
\hline & Aluminium sickle & Spring steel sickle \\
\hline & RM76.82 & RM150.00 \\
\hline Economic life & \multicolumn{2}{|c|}{1 year } \\
\hline Working days per year & \multicolumn{2}{|c|}{300 days } \\
\hline Depreciation (Price $/($ Life span $\times$ Working days)) & $\mathrm{RM} 0.25$ & $\mathrm{RM} 0.50$ \\
\hline Labour cost & \multicolumn{2}{|c|}{ RM50/day } \\
\hline Productivity & \multicolumn{2}{|c|}{$6 \mathrm{t} /$ day } \\
\hline Total cost per day (Labour cost + Depreciation) & RM50.25 & RM50.50 \\
\hline Cost per tonne $=$ Total cost $/$ Productivity & RM8.37/t FFB & RM8.42/t FFB \\
\hline
\end{tabular}

\section{CONCLUSION}

Based on the simulation done using the FEM software, it can be concluded that 6262-T8 aluminium alloy is not suitable as a material for CANTAS sickle blade if the original sickle design is applied. The amount of stress generated by the cutting load of $300 \mathrm{~N}$ (i.e., $1203 \mathrm{MPa}$ ) exceeds the material's ultimate tensile strength value. Hence, mechanical failure will occur due to high stress and the sickle will break.

However, aluminium alloy can still be used as the sickle blade material if the design is improved by strengthening the weak points on the sickle blade. By increasing the width of the sickle bottom neck by $25 \%$, the stress value experienced by the sickle had reduced up to $314 \mathrm{MPa}$, which did not exceed its material ultimate tensile strength value. This showed that strengthening the neck of the sickle was able to eliminate the weak point identified earlier. However, by applying this improvement, the weight of the sickle had increased slightly by $2 \%$ to $70.45 \mathrm{~g}$, from the initial weight of 68.98 . To further reduce its weight, several relief holes have been strategically placed in areas that does not experience any stress. Consequently, the weight of the sickle blade was reduced to $62.36 \mathrm{~g}$ (i.e., $68.6 \%$ of weight reduction compared to spring steel sickle).

Another FEM simulation was conducted to verify that the latest design improvement (i.e., addition of relief holes) does not weaken the structure. The simulation showed that the latest sickle design experienced only up to $356.92 \mathrm{MPa}$ of stress which still did not exceed the material's ultimate tensile strength value. Hence, the failure potential for the sickle material is still avoidable. Finally, a drop test analysis was performed using the sickle to prove that the sickle would not be damaged if it drops to the ground. The drop test simulation results showed that the sickle only experienced stress load between 1.117 to 131.03 $\mathrm{MPa}$ only, and therefore, confirmed that the aluminium alloy sickle could withstand the drop impact. An economic analysis was also carried out to determine its cost-efficiency had indicated that, the cost per tonne required by the plantation is $\mathrm{RM} 8.37 / \mathrm{t}$ of $\mathrm{FFB}$ when using the aluminium alloy, compared to RM8.42/t of FFB when using the conventional spring steel. Although the cost reduction is only about $0.6 \%, 6262-\mathrm{T} 8$ aluminium alloy sickle is still considered advantageous in terms of being lightweight, and resistant to corrosion and vibration. Therefore, based on this study, an optimised CANTAS sickle blade design using 6262-T8 aluminium alloy has better advantages in comparison to the conventional spring steel sickle and it is suitable for application in an oil palm plantation.

\section{ACKNOWLEDGEMENT}

The authors would like to express their sincere gratitude to the management of Malaysian Palm Oil Board (MPOB) to allow this article to be published, as well as to those who have involved and contributed in this research either directly or indirectly.

\section{REFERENCES}

Ahmad, M R; Jamaludin, N; Jelani, A R; Bakri, Azwan and Shuib, A R (2020). The effect of design parameters on force and energy requirements for cutting oil palm fronds. Jurnal Teknologi, 82(4): DOI: 10.11113 /jt.v82.14236.

Alonso-Martinez, M; Adam, J M; Alvarez-Rabanal, F P and del Coz Díaz, J J (2019). Wind turbine tower collapse due to flange failure: FEM and DOE analyses. Eng. Fail. Anal., 104: 932-949. DOI: 10.1016/j.engfailanal.2019.06.045.

Andreoni, W and Yip, S (2020). Handbook of Materials Modeling. Applications: Current and Emerging Materials. Second edition. Springer. p. 74-76. 
Azwan, M B; Norasikin, A L; Sopian, K; Abd Rahim, S; Norman, K; Ramdhan, K and Solah, D (2017). Assessment of electric vehicle and photovoltaic integration for oil palm mechanisation practise. J. Clean. Prod., 140: 1365-1375. DOI: 10.1016/j. jclepro.2016.10.016.

Basiron, Y (2007). Palm oil production through sustainable plantations. Eur. J. Lipid Sci. Technol., 109(4): 289-295.

Castaldo, P; Nastri, E and Piluso, V (2017). FEM simulations and rotation capacity evaluation for RHS temper T4 aluminium alloy beams. Compos. B Eng., 115: 124-137. DOI: 10.1016/j. compositesb.2016.10.026.

Dahlan, I (2000). Oil palm frond, a feed for herbivores. Asian-Australas. J. Anim. Sci., 13: 300-303.

Gardner, L and Ashraf, M (2006). Structural design for non-linear metallic materials. Eng. Struct., 28(6): 926-934.

Gunturi, C; Escobedo, J P and Islam, M A (2019). Comparative analysis of dynamic impact tests between the charpy $\mathrm{V}$-notch test and the drop tower test. Characterization of Minerals, Metals and Materials 2019 Springer, Cham. p. 553-560. DOI: 10.1007 / $978-$ 3-030-05749-7.

Harish, A (2019). Simscale. https: / www.simscale. com / blog / 2016/10/what-is-finite-elementmethod/, accessed on 3 February 2020.

Jelani, A R; Ahmad, D; Hitam, A; Yahya, A and Jamak, J (1998). Force and energy requirements for cutting oil palm frond. J. Oil Palm Res., 10(2): 10-24.

Jelani, A R; Hitam, A; Jamak, J; Noor, M; Gono, Y and Ariffin, $\mathrm{O}$ (2008). Cantas $^{\mathrm{TM}}-\mathrm{A}$ tool for the efficient harvesting of oil palm fresh fruit bunches. J. Oil Palm Res., 20: 548-558.

Kuznetsova, A; Yates, J T; Zhou, G; Yang, J C and Chen, X (2001). Making a superior oxide corrosion passivation layer on aluminum using ozone. Langmuir, 17(7): 2146-2152. DOI: 10.1021/la001300x.

Lin, X B and Smith, R A (1998). Fatigue growth simulation for cracks in notched and unnotched round bars. Int. J. Mech. Sci., 40(5): 405-419.

Lüders, K and Pohl, R O (2017). Pohl's Introduction to Physics. Volume 1: Mechanics, Acoustics and Thermodynamics (Klaus, L; Robert, OP and Williams, D B eds.). Springer. p. 19.

MakeItFrom (2019). MakeItFrom.com. https:/ / www.makeitfrom.com / material-properties / 6262T8-Aluminum, accessed on 3 February 2020.

Parveez, G K A; Elina, H; Soh, K L; Meilina, O A; Kamalrudin, M S; Bidin, M N I Z; Sundram, S; Hasan, Z A A and Idris, Z (2020). Oil palm economic performance in Malaysia and R\&D progress in 2019. J. Oil Palm Res., 32(2): 159-190. DOI: 10.21894/ jopr.2020.0032.

Rusinek, R; Wiercigroch, M and Wahi, P (2014). Modelling of frictional chatter in metal cutting. Int. J. Mech. Sci., 89: 167-176.

Salleh, S M; Rahim, E A; Roslan, M N; Ismon, M; Madlan, M A; Masrol, S R; Jelani, A R and Ahmad, M R (2013). Hand-arm vibration of unskilled oil palm motorised cutter operator. Appl. Mech. Mater., 315: 695-699. DOI: 10.4028/www.scientific.net/ AMM.315.695.

The Material World (2020). The Material World. https: / / www.theworldmaterial.com / sae-aisi5160-high-carbon-spring-steel/, accessed on 3 February 2020.

Winn, W (2010). Introduction to Understandable Physics: Modern and Frontier Physics: Volume IV Modern and Frontier Physics. AuthorHouse. 444 pp.

Zerbst, U; Klinger, C and Clegg, R (2015). Fracture mechanics as a tool in failure analysis - Prospects and limitations. Eng. Fail. Anal., 55: 376-410. DOI: 10.1016/j.engfailanal.2015.07.001. 